\title{
Once-Daily Tacrolimus Extended-Release Formulation: 1 Year after Conversion in Stable Pediatric Kidney Transplant Recipients
}

\author{
Lars Pape, Nele Heidotting, and Thurid Ahlenstiel \\ Department of Pediatric Nephrology, Hannover Medical School, 30625 Hannover, Germany \\ Correspondence should be addressed to Lars Pape, larspape@t-online.de
}

Received 26 January 2011; Revised 21 March 2011; Accepted 22 March 2011

Academic Editor: Michel Fischbach

Copyright () 2011 Lars Pape et al. This is an open access article distributed under the Creative Commons Attribution License, which permits unrestricted use, distribution, and reproduction in any medium, provided the original work is properly cited.

It is speculated that a once-daily dosage of immunosuppression can increase adherence and thereby graft survival. Until now, there have been no studies on once-daily use of Tacrolimus extended-release formulation (TAC-ER) in children following pediatric kidney transplantation. In 11 stable pediatric kidney recipients $>10$ years, efficacy, safety, and tolerability of a switch to TAC-ER were observed over one year. Adherence was determined by use of the BAASIS-Scale Interview and comparison of individual variability of Tacrolimus trough levels. Over the observation period, two acute rejections were observed in one girl with nonadherence and repeated Tacrolimus trough levels of $0 \mathrm{ng} / \mathrm{m}$. Beside this, there were no acute rejections in this trial. TAC dose was increased in 3/11 patients and decreased in 2/11 patients within the course of the study. Six patients did not require a dose adjustment. All but one patient had a maximum of 1 dose change during therapy. Mean Tacrolimus dose, trough levels, and Glomerular filtration rates were also stable. Adherence, as measured by BAASIS-Scale Interview and coefficient of variation of Tacrolimus trough levels, was good at all times. It is concluded that conversion to Tac-ER is safe in low-risk children following pediatric kidney transplantation.

\section{Introduction}

Patient nonadherence to immunosuppressive therapy after kidney transplantation is an important factor contributing to acute rejection and decreased graft survival [1-5]. This is especially true for adolescents [1] who are at the highest risk of nonadherence. Fennell et al. indicated that approximately $50 \%$ of children with chronic diseases are nonadherent [6]. It has been shown that, following pediatric renal transplantation, nonadherence is one of the most important contributing factors for graft rejection and loss [7]. In renal transplantation in adults one study concluded that there was a statistically significant correlation between a oncedaily dose of immunosuppression and better adherence [2]. However, until now, there has been no evidence that TACER improves adherence to the immunosuppressive regimen. In other meta-analyses there is only limited evidence that once-daily dosing of a drug improves adherence to the immunosuppressive regimen in other chronic diseases $[8,9]$. A once-daily dose of Tacrolimus extended-release formulation (TAC-ER) was safe and effective in a small cohort of children after liver transplantation [10]. No such data exists for children after kidney transplantation.

\section{Patients and Methods}

2.1. Study Design. This was an open-label, controlled prospective trial to determine the safety and efficacy of the use of one daily TAC-ER dose in children after kidney transplantation and to improve adherence. The study was performed in accordance with the ethics committee of Hannover Medical School. It was classified as a "noninvasive prospective trial" by the ethics committee according to German law that does not require registration. Therefore, ICH-GCP guidelines were followed partially as required: serious adverse events and adverse events were documented, but no external monitoring was implemented. Informed consent was given by parents and children. The study was conducted as an investigator initiated trial. Sponsor of the study was the Medical School of Hannover, Germany.

As this was the first trial with TAC-ER in children after kidney transplantation, a selected low-risk study group was 
chosen: children $>10$ years with a minimum of one year since kidney transplantation and with stable renal function were eligible for the study. No acute rejections occurred within the year before the study. Immunosuppression consisted of either Cyclosporine A (CsA) and Mycophenolate Mofetil $(\mathrm{MMF}) \pm$ Prednisolone or Tacrolimus (TAC), $\mathrm{MMF} \pm$ Prednisolone. After conversion all participants were continued on MMF twice daily in addition to Tac-ER and Prednisolone once daily. The patients were studied from January 2008 to January 2009. Observation time was one year.

The study was a conversion study. At study initiation the dose of TAC-ER was calculated as the prior daily dose of Tacrolimus. In cases of CsA therapy, daily TAC-ER dose was calculated as follows: $6 \mathrm{mg} / \mathrm{m}^{2}$ body surface area. Target Tacrolimus trough level was $5-7 \mu \mathrm{g} / \mathrm{L}$. All patients were seen in the outpatient clinic one week after the conversion and then every 4 weeks for the rest of the study period. No surveillance biopsies were performed. Indication biopsies were mandatory in cases of increased creatinine of 15\% over baseline.

In all patients the Basel assessment of adherence to immunosuppressive medication scale (BAASIS Scale) was done by interview at study initiation and one year later. The BAASIS Scale is a combination of the Siegal questionnaire [11] and the self-report on adherence of Walsh et al. [12]. The assessment was completed with the patients, not their parents.

The incidence of biopsy-confirmed acute rejection episodes, patient and graft survival rate was assessed throughout the study. Safety was assessed based on individual adverse events and the results of routine clinical laboratory tests and assessment of vital signs.

2.2. Patients. Twelve children (age $>10$ years) were eligible for the study. One family refused consent to the study because of the stable situation of their child. Eleven children, mean age $14 \pm 2$ years, 4 female, 7 male, were included in the study. Complete demographics are given in Table 1. Ten patients were treated with TAC, MMF \pm Prednisolone before study start and one with CsA, MMF, and Prednisolone.

2.3. Statistics. Primary endpoint of the study was an improvement of adherence as demonstrated by an increase of mean percentage of self-estimated compliance after Walsh et al. [12]. Sample size was calculated as follows: estimated mean percentage of adherence before switch $85 \%$, after switch $95 \%$, sample size 10 patients, standard deviation $7 \%$, and $\alpha$ error 5\%. Statistical Power was calculated as $93.9 \%$.

In order to calculate the intraindividual variability of TAC trough levels, the last 5 trough levels before the switch and before the end of the first year after the switch measured every 4 weeks were used to calculate the individual coefficients of variation $(\mathrm{CV}=$ standard deviation $/$ mean $)$. Five outpatient trough levels with an interval of 4 weeks were used. No values were excluded. Based on these values, the mean coefficient of variation was calculated for both assessments. Values between different assessments were compared by paired $t$-test and those between patients by unpaired $t$ test. $P<.05$ was defined as statistically significant.
Table 1: Patient demographics.

\begin{tabular}{ll}
\hline Gender & Male 7, female 5 \\
Mean age & $\begin{array}{l}14 \pm 2 \text { years } \\
\text { CsA/MMF: } n=1\end{array}$ \\
$\begin{array}{l}\text { Immunosuppressant before } \\
\text { switch }\end{array}$ & TAC/MMF: $n=10$ \\
& pANCA-positive vasculitis: $n=2$ \\
& $\begin{array}{l}\text { Renal dysplasia: } n=5 \\
\text { Nephronophthisis: } n=2\end{array}$ \\
Underlying disease & $\begin{array}{l}\text { Obstructive uropathy: } n=1 \\
\text { Congenital nephrotic syndrome: } \\
n=1\end{array}$ \\
& $4 / 7$ \\
$\begin{array}{l}\text { Living donation/cadaveric } \\
\text { donation }\end{array}$ & $4.4 \pm 2.6$ years \\
$\begin{array}{l}\text { Mean time from } \\
\text { transplantation to switch }\end{array}$ &
\end{tabular}

Adverse events and serious adverse events were documented according to clinical practice guidelines.

\section{Results}

3.1. Tacrolimus Drug Exposure. Mean daily TAC dose was $4.8 \pm 2.2 \mathrm{mg} / \mathrm{m}^{2}$ before the switch and $5.1 \pm 2.4 \mathrm{mg} / \mathrm{m}^{2}(P=$ n.s.) one year later. Mean trough levels were $6.2 \pm 2.0 \mathrm{ng} / \mathrm{mL}$ before the switch and $6.5 \pm 0.9 \mathrm{ng} / \mathrm{mL}$ one year later. TAC dose was increased in $3 / 11$ patients and decreased in $2 / 11$ patients within the course of the study. Six patients did not require a dose adjustment. All but one patient had a maximum of 1 dose change during therapy. The adjunctive immunosuppressive therapies were not changed during the study.

3.2. Kidney Function. The mean GFR (abbreviated Schwartz 2009 formula [13]) was $56 \pm 11 \mathrm{~mL} / \mathrm{min} / 1.73 \mathrm{~m}^{2}$ at time of switch and $55 \pm 11 \mathrm{~mL} / \mathrm{min} / 1.73 \mathrm{~m}^{2}$ one year later $(P=$ n.s. $)$. There was no graft loss or patient death.

3.3. Acute Rejection. Indication biopsies due to an increase in s-creatinine were only performed in one 16-year-old girl. Both biopsies showed acute rejection, BANFF Grade Ia. In both, TAC levels were $0 \mathrm{ng} / \mathrm{mL}$, and the patient reported not having taken TAC-ER due to psychosocial problems. Both acute rejection episodes were sensitive to steroid pulses. After multiple intervention by the psychosocial team, adherence increased and TAC levels were stable.

3.4. Intraindividual Variability of Tacrolimus Levels. The mean coefficient of variation of TAC trough levels was $0.27 \pm 0.11$ before the switch and $0.30 \pm 0.19$ one year later $(P=$ n.s. $)$.

3.5. BAASIS Scale. The results of the BAASIS-Scale Interview were comparable at both times of evaluation. Results of the important items are given in Table 2. 
TABLE 2: Results of The BAASIS-Scale Interview concerning adherence in all patients before the switch to TAC-ER and one year later.

\begin{tabular}{|c|c|c|c|}
\hline & Before switch to TAC-ER & One year after switch & $P$ \\
\hline Immunosuppression not taken & 3/20: once monthly & 3/20: once monthly & n.s. \\
\hline \multirow{2}{*}{ Immunosuppression taken $2 \mathrm{hrs}$ before or after prescribed time } & 3/20: once monthly & 2/20: once monthly & \multirow{2}{*}{ n.s. } \\
\hline & 2/20: once every 2 weeks & 1/20: once every 2 weeks & \\
\hline Dose of Immunosuppression changed without advice & $0 / 20$ & $0 / 20$ & n.s. \\
\hline Mean percentage of self-estimated compliance after Walsh et al. [12] & $94 \pm 7 \%$ & $93 \pm 7 \%$ & n.s. \\
\hline
\end{tabular}

3.6. Serious Adverse Events. Two hospital admissions for 2 indication kidney biopsies in one 16-year-old girl and one admission in a 17 -year-old boy due to gastroenteritis requiring i.v. rehydration took place. No other serious adverse events were documented during the study period.

\section{Discussion}

This data concludes that, in a selected cohort of pediatric kidney recipients, a switch from the standard formulation TAC to TAC-ER is safe. The acute rejection episodes taking place in one patient were due to nonadherence and interaction problems within her family. Despite this nonadherence, mean GFR remained stable, intraindividual variability of trough level was low, and TAC-ER was not discontinued in any patient. One dose adjustment of TAC-ER had to be performed in $45 \%$ of the patients.

In adults receiving antihypertensive medication, it has been shown that adherence can be increased from 59\% to $83 \%$ when changing from a thrice-daily dose to a once-daily dose of medication [14]. These findings have been confirmed by Weng et al. [2] who used electronically measured adherence to immunosuppressive therapy. Wolff et al. studied the issue of medication adherence in 85 children with endstage renal disease and found that, in $4 \%$ of the patients, nonadherence had been the primary reason for referral to psychosocial services [1]. They concluded that nonadherence is almost inevitable, often based on valid personal reasons. It has been shown that adherence and education influence the nephrologists' recommendation for transplantation [15]. In a meta-analysis, Dobbels et al. calculated a mean nonadherence rate of $35.2 \%$ in children after renal transplantation. They stated that adherence-enhancing interventions should consist of educational strategies, behavioural strategies, and strategies to increase social support [16]. Rianthavorn and Ettenger [7] described different methods of documenting medication nonadherence and stated standard deviation calculation for trough levels of TAC, as described by others [17], to be highly correlated with outcomes that suggested nonadherence, such as biopsy proven rejection. In this study the coefficient of variation of TAC trough levels was low even before study initiation and did not change thereafter in comparison to other immunosuppressive studies [18]. The girl who did not take her medication in the middle of the study period did not influence the low mean coefficient of variation, because for calculation purposes it was defined before study start that only trough levels before the switch and in the last months of the study period were used. In these two periods, TAC trough levels were stable in this girl.

The primary endpoint, showing superiority for adherence after switch to once-daily dosing, was not achieved within our study. The "good adherence" at the beginning of the study might explain why there was no more increase in adherence after the switch to TAC-ER. Obviously, there was a selection bias of adherent children in the study, only including children without acute rejection one year before the switch. However, this bias was accepted when designing the study, as stable patients for the first change to a new immunosuppressant was a requirement. In this study only children $>10$ years were included, because major differences in pharmacokinetics can be expected in children below this age.

Another aspect for the failure of this study to achieve more adherence may have been the combination of TAC-ER with MMF, which has to be administered twice daily. Future studies with TAC-ER in children should include teenagers with a history of nonadherence and also children $<10$ years. In a future study with a more high-risk population, careful pharmacokinetic monitoring should be mandatory. The possible positive effect of TAC-ER on adherence could be enhanced by immunosuppressive combinations needing only once-daily application for all agents. However, possible combinations such as TAC-ER and Sirolimus or TAC-ER and Azathioprine have not shown promising results in children until now and should not therefore be used in future studies.

In studies in adults, it could be demonstrated that the pharmacokinetic profile of TAC-ER is different compared to TAC. In several adults TAC-ER dose has to be increased after switch from TAC to TAC-ER to obtain the same exposure to Tacrolimus [19]. In this small pediatric cohort, dose had to be increased in $3 / 11$ children. However, administration of TAC-ER in conversion studies in adults was also safe for the patients [20,21].

It is concluded that TAC-ER can safely be used in a selected low-risk cohort of pediatric kidney graft recipients $>10$ years. In this selected study population, adherence could not be improved by once-daily administration of TAC.

\section{Abbreviations}

GFR: Glomerular filtration rate

TAC: Tacrolimus 
TAC-ER: Tacrolimus extended-release

MMF: Mycophenolate Mofetil

CsA: Cyclosporine A

mTOR: Mammalian target of rapamycin.

\section{Acknowledgment}

The study was supported by an unrestricted grant by Astellas, Germany.

\section{References}

[1] G. Wolff, K. Strecker, U. Vester, K. Latta, and J. H. H. Ehrich, "Non-compliance following renal transplantation in children and adolescents," Pediatric Nephrology, vol. 12, no. 9, pp. 703708, 1998.

[2] F. L. Weng, A. K. Israni, M. M. Joffe et al., "Race and electronically measured adherence to immunosuppressive medications after deceased donor renal transplantation," Journal of the American Society of Nephrology, vol. 16, no. 6, pp. 1839-1848, 2005.

[3] B. R. Siegal and S. M. Greenstein, "Postrenal transplant compliance from the perspective of African- Americans, hispanic-americans, and anglo-americans," Advances in Renal Replacement Therapy, vol. 4, no. 1, pp. 46-54, 1997.

[4] L. B. Hilbrands, A. J. Hoitsma, and R. A. P. Koene, "Medication compliance after renal transplantation," Transplantation, vol. 60, no. 9, pp. 914-920, 1995.

[5] I. Sketris, N. Waite, K. Grobler, M. West, and S. Gerus, "Factors affecting compliance with cyclosporine in adult renal transplant patients," Transplantation Proceedings, vol. 26, no. 5, pp. 2538-2541, 1994.

[6] R. S. Fennell, L. M. Foulkes, and S. R. Boggs, "Familybased program to promote medication compliance in renal transplant children," Transplantation Proceedings, vol. 26, no. 1, pp. 102-103, 1994.

[7] P. Rianthavorn and R. B. Ettenger, "Medication nonadherence in the adolescent renal transplant recipient: a clinician's viewpoint," Pediatric Transplantation, vol. 9, no. 3, pp. 398-407, 2005.

[8] S. Kripalani, X. Yao, and R. B. Haynes, "Interventions to enhance medication adherence in chronic medical conditions: a systematic review," Archives of Internal Medicine, vol. 167, no. 6, pp. 540-550, 2007.

[9] S. D. Saini, P. Schoenfeld, K. Kaulback, and M. C. Dubinsky, "Effect of medication dosing frequency on adherence in chronic diseases," The American Journal of Managed Care, vol. 15, no. 6, pp. e22-e33, 2009.

[10] T. G. Heffron, M. D. Pescovitz, S. Florman et al., "Oncedaily tacrolimus extended-release formulation: 1-Year postconversion in stable pediatric liver transplant recipients," American Journal of Transplantation, vol. 7, no. 6, pp. 16091615, 2007.

[11] B. R. Siegal, "Postrenal transplant compliance: report of 519 responses to a self-report questionnaire," Transplantation Proceedings, vol. 25, no. 4, p. 2502, 1993.

[12] J. C. Walsh, S. Mandalia, and B. G. Gazzard, "Responses to a 1 month self-report on adherence to antiretroviral therapy are consistent with electronic data and virological treatment outcome," AIDS, vol. 16, no. 2, pp. 269-277, 2002.

[13] G. J. Schwartz, A. Muñoz, M. F. Schneider et al., "New equations to estimate GFR in children with CKD," Journal of the American Society of Nephrology, vol. 20, no. 3, pp. 629-637, 2009.

[14] S. A. Eisen, D. K. Miller, R. S. Woodward, . Spitznagel, and T. R. Przybeck, "The effect of prescribed daily dose frequency on patient medication compliance," Archives of Internal Medicine, vol. 150, no. 9, pp. 1881-1884, 1990.

[15] S. L. Furth, W. Hwang, A. M. Neu, B. A. Fivush, and N. R. Powe, "Effects of patient compliance, parental education and race on nephrologists' recommendations for kidney transplantation in children," American Journal of Transplantation, vol. 3, no. 1, pp. 28-34, 2003.

[16] F. Dobbels, R. Van Damme-Lombaert, J. Vanhaecke, and S. De Geest, "Growing pains: non-adherence with the immunosuppressive regimen in adolescent transplant recipients," Pediatric Transplantation, vol. 9, no. 3, pp. 381-390, 2005.

[17] E. Shemesh, B. L. Shneider, J. K. Savitzky et al., "Medication adherence in pediatric and adolescent liver transplant recipients," Pediatrics, vol. 113, no. 4 I, pp. 825-832, 2004.

[18] L. Pape, J. H. H. Ehrich, and G. Offner, "Advantages of cyclosporin A using 2-h levels in pediatric kidney transplantation," Pediatric Nephrology, vol. 19, no. 9, pp. 1035-1038, 2004.

[19] M. Crespo, M. Mir, M. Marin et al., "De novo kidney transplant recipients need higher doses of Advagraf compared with Prograf to get therapeutic levels," Transplantation Proceedings, vol. 41, no. 6, pp. 2115-2117, 2009.

[20] M. R. First, "First clinical experience with the new once-daily formulation of tacrolimus," Therapeutic Drug Monitoring, vol. 30, no. 2, pp. 159-166, 2008.

[21] R. Alloway, S. Steinberg, K. Khalil et al., "Two years postconversion from a prograf-based regimen to a once-daily tacrolimus extended-release formulation in stable kidney transplant recipients," Transplantation, vol. 83, no. 12, pp. 1648-1651, 2007. 


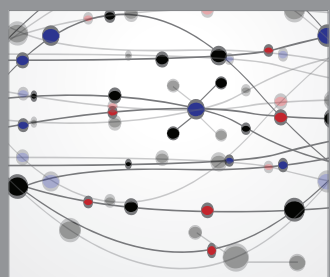

The Scientific World Journal
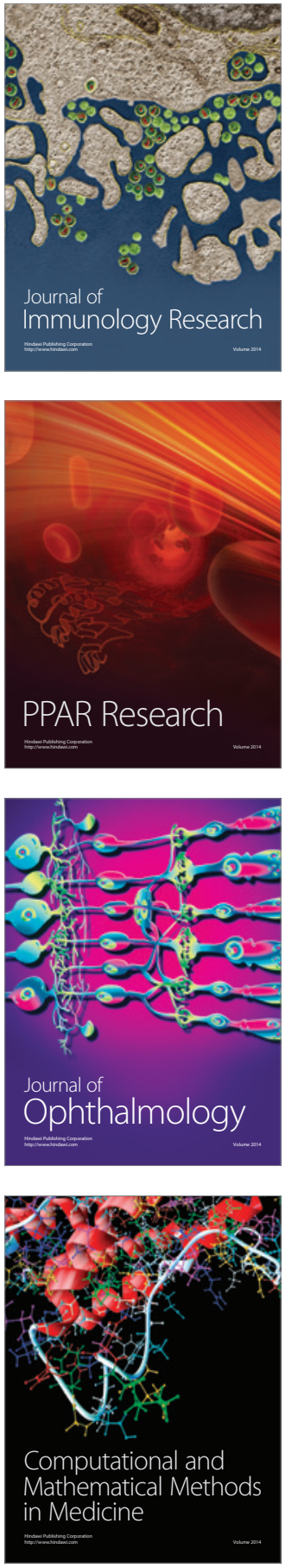

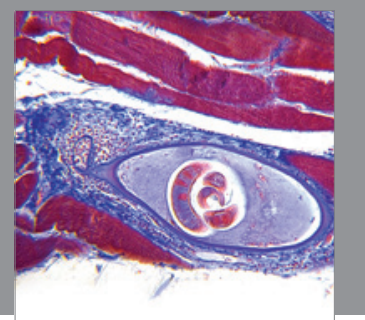

Gastroenterology

Research and Practice
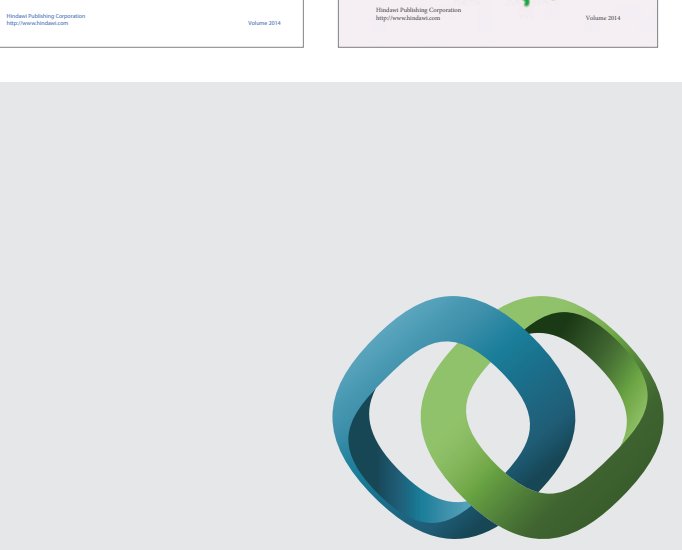

\section{Hindawi}

Submit your manuscripts at

http://www.hindawi.com
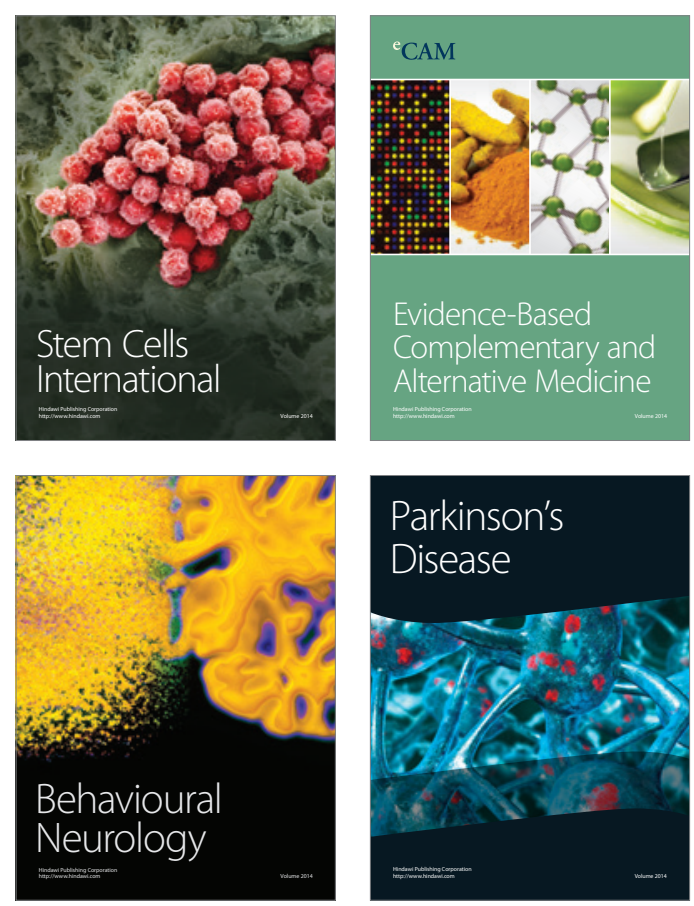

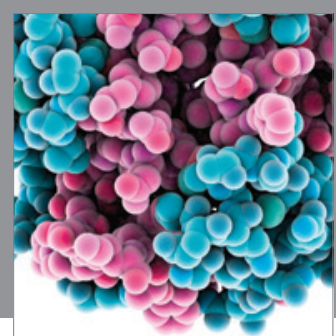

Journal of
Diabetes Research

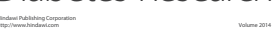

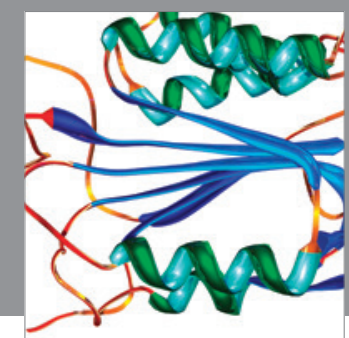

Disease Markers
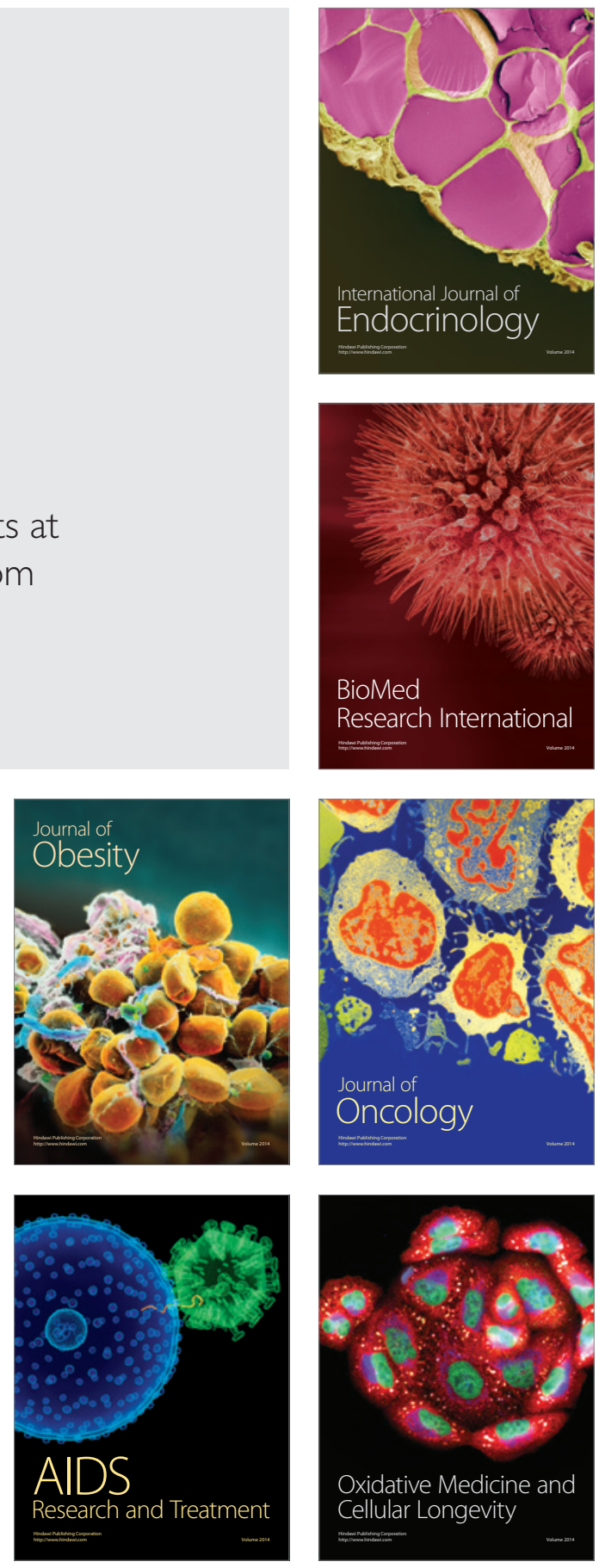